\title{
A Multidisciplinary Sea-floor Observatory in the Northern Gulf of Mexico: Results of Preliminary Studies
}

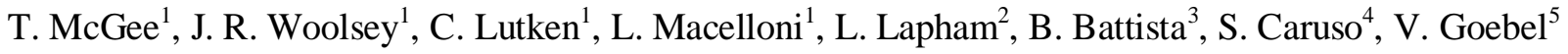 \\ ${ }^{1}$ Center for Marine Resources and Environmental Technology, University of Mississippi \\ ${ }^{2}$ Department of Oceanography, Florida State University \\ ${ }^{3}$ Department of Geological Sciences, University of South Carolina \\ ${ }^{4}$ Department of Earth Sciences, University of Rome "La Sapienza" \\ ${ }^{5}$ Lookout Geophysical Company, Palisade, Colorado
}

\begin{abstract}
Discussion of results of preliminary studies at the sea-floor observatory site in the Northern Gulf of Mexico.
\end{abstract}

\section{INTRODUCTION}

A carbonate/hydrate mound in Mississippi Canyon Lease Block 118 (MC118) has been chosen by the Gulf of Mexico Hydrates Research Consortium to be the site of a sea-floor observatory. The location of MC118 is shown in fig.1. The observatory is designed to include seismoacoustic, geochemical and micro-biologic sensors to monitor ambient noise, fluid venting and environmental conditions. The observations are expected to promote a better understanding of how fluids migrate within the mound and affect the formation/dissociation of hydrates. The following discusses observations made in preparation for installing the observatory.

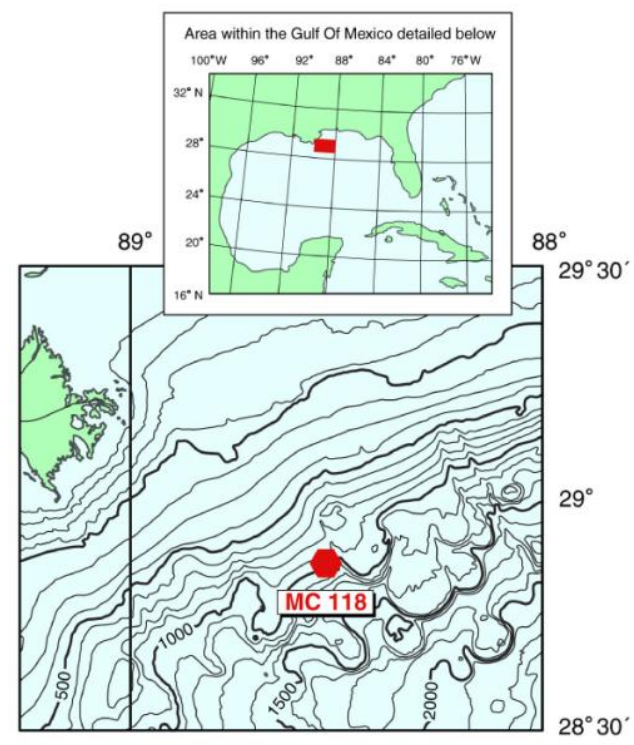

Fig.1 - Location of MC118

\section{SURFACE MORPHOLOGY}

The mound is approximately one kilometer in diameter and is located in nearly $900 \mathrm{~m}$ of water. Its surface has been imaged by multi-beam bathymetric sonar from an AUV $40 \mathrm{~m}$ above the sea floor and by cameras at, or a few meters above, the sea floor. In addition, direct visual observations were made from manned submersibles.

The surface morphology (fig.2) is characterized by clusters of craters that exhibit $2-6 \mathrm{~m}$ bathymetric relief with individual craters being $5-60 \mathrm{~m}$ in diameter. For discussion purposes, the clusters are grouped into three principle complexes based on bathymetric relief and relative venting activity. The three complexes are: the SE Complex which has low relief and no observable venting activity; the SW Complex which exhibits moderate-to-high relief and the most active vents on the mound; and the NW Complex with moderate-to-low relief and a moderate-to-low level of venting.

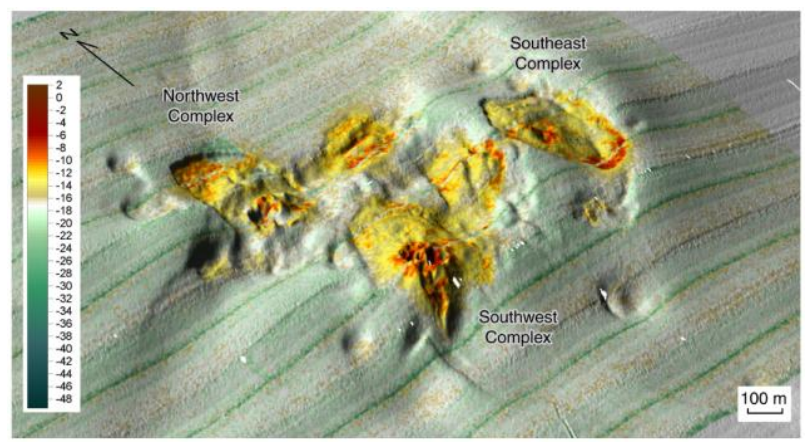

Fig.2 - Backscatter image of swath bathymetry recorded from an AUV 
It is noteworthy that, although the SE Complex exhibits little activity at present, it contains extensive pavements of methanotrophic clam shells which provide evidence of past activity. Fluid expulsion events appear to occur episodically in the SW and NW Complexes where they are probably responsible for crater formation as well as for maintaining bottom relief despite burial effects of fine-particulate sedimentation.

\section{GAS COMPOSITION}

Gas samples have been collected in the SW Complex from three vents and one intact piece of outcropping hydrate. Chemical analyses [1] show the vent gas to be thermogenic from deep hot source rocks and to average 95\% methane, $3 \%$ ethane, $1 \%$ propane with minor other gases. There is no significant biogenic component. The outcropping hydrate is Structure II with gas composition $70 \%$ methane, $7.5 \%$ ethane, $15.9 \%$ propane with minor other gases. The difference between the gas compositions from the vents and the hydrate is due to molecular fractionation during hydrate crystallization (Sassen, pers. com.).

\section{LITHOLOGIC AND BIO-GEOCHEMICAL STUDIES}

Gravity and box cores have been collected for lithologic and bio-geochemical studies. Mound lithology is mainly Recent hemipelagic mud with poorly cemented, bioencrusted/eroded, authigenic carbonate rocks of various sizes in the $10 \mathrm{~cm}-5 \mathrm{~m}$ range [2]. The rocks are scattered over the mound surface and support deep-water corals at some sites in the SW and NW Complexes. Typically, the mud surfaces of crater sites are littered with fragments of methanotrophic clam shells. In some areas, particularly in and around quiescent vent sites, such shells pave the sea floor.

Carbonate rocks on crater floors typically occur as tabular blocks $(0.5-4 \mathrm{~m})$. They commonly form a uniformly horizontal surface and occur at a common elevation throughout the SW Complex. Relatively fresh exposures in the western part of the SW Complex outcrop from a thin $(50 \mathrm{~cm}-2 \mathrm{~m})$ overburden of hemipelagic mud, apparently exposed by the winnowing effect of episodic fluid expulsion events. These often host gas hydrates which are visible as irregular inclusions in void spaces and, rarely, as interbedded tabular slabs.

The presence of authigenic carbonates is intimately related to the activity of sedimentary microbes and bacterial mats on the sediment surface. Bacterial mats thought to be the sulfide-oxidizing Beggiatoa are common on the mound surface. They are observed more often in stable, flat-lying, extra-crater areas and only rarely within more active, inherently unstable craters. Bacterial mats are linked to the precipitation/formation of authigenic carbonate rocks. The overall contribution of resident microbial communities, surface and subsurface, to the geology of the hydrate mounds is only recently being investigated and their critical role in hydrate-mound evolution just now beginning to be fully appreciated.

\section{VENTING ACTIVITY}

Proprietary deep seismic data clearly show a salt diapir some hundreds of meters beneath the sea floor that is connected to the mound by a system of nearly vertical fractures. This system appears to provide conduits through which hydrocarbon fluids from deep sources reach the mound.

The lack of evidence for recent venting in the SE Complex suggests that the conduits which once supplied sufficient methane to support an abundant population of methanotrophic clams have become blocked. It is hypothesized that the blockage is due to hydrates forming within the fractures. If so, gases that continue to rise would follow routes that bypass the blockage and emerge elsewhere on the mound.

The SW Complex contains the most active of the mound's craters in terms of venting activity and active expulsion features. It is divided into western and eastern parts separated by a ridge of fine-grained material that overlies a well-defined horizon of authigenic carbonate. That horizon consists of sub-horizontal tabular blocks about $1 \mathrm{~m}$ thick. In the western part, these blocks pave the floors of craters and are characterized by inclusions of hydrate that fill voids within the carbonate. In some places, streams of gas bubbles rise from between blocks. In the eastern part, oil in various stages of microbial degradation occurs abundantly in fine sediments on the crater floors. A large $(6 \mathrm{mx} 2 \mathrm{mx} 1.5 \mathrm{~m})$ carbonate/hydrate outcrop was seen to protrude from the eastern flank of one crater but, when revisited 14 months later, was found to have been reduced by about $70 \%$. A discontinuous low-relief depression crossing the eastern part of the SW Complex appears to be the trace of a tensional fracture with SW-NE orientation. Two vertical dykes of hydrate, each approximately $1 \mathrm{~m}$ high, $1 \mathrm{~m}$ long and $30-50 \mathrm{~cm}$ thick were seen protruding from the depression, apparently having formed within the fracture.

In the NW Complex, venting is not vigorous but there is evidence of a low-to-moderate level of activity. A recording pore-fluid array probe installed there measured salinities five times higher than that of sea water. A small bubble stream was observed and nearby in-situ mass-spectrometer measurements indicated watercolumn methane approaching saturation. The presence of extensive bacterial mats suggests that methane is seeping from bottom sediment throughout the vicinity. Notably, a pore-fluid array in the NW Complex recorded a sharp spike in methane on 10 September, 2006, when a magnitude 5 earthquake occurred some $80 \mathrm{~km}$ south. 
Two days later, observers aboard a manned submersible found that a crater, approximately $10 \mathrm{~m}$ diameter and $3 \mathrm{~m}$ deep, had developed in the center of the NW Complex.

\section{SEISMO-ACOUSTIC STUDIES}

The sub-surface structure of the mound has been investigated using a number of seismo-acoustic techniques. Chirp-sonar profiles at $200 \mathrm{~m}$ line spacing were recorded simultaneously with the AUV swathbathymetry data. These profiles provide about $30 \mathrm{~m}$ penetration at sub-meter resolution except in portions of the mound where strong backscatter occurs at shallow depths, apparently caused by heterogeneities such as blocks of carbonate/hydrate and zones of free gas.

A grid of seismic profiles was acquired at 50-by$100 \mathrm{~m}$ line spacing using the shallow source/deep receiver (SSDR) field geometry [2]. It places a strong acoustic source near the surface of the water directly above a hydrophone receiver deployed several hundred meters below. The out-going wave front locally approximates a vertically traveling plane wave as it impinges on the receiver and is recorded as a far-field source signature for each shot. During post processing, the phase of the signature is removed, spherical divergence corrections are applied and the scale of individual traces calibrated to allow calculation of normal-incidence $\mathrm{p}$-wave reflection coefficients. This improves seismic resolution throughout the depth of useful penetration which is limited by the arrival of the surface "ghost" reflection.

Using an $80 \mathrm{in}^{3}$ water-gun source, the grid of SSDR profiles provided several hundred meters of useful penetration. This was sufficient to image sub-bottom structure to below the base of the hydrate stability zone (BHSZ) at meter-scale resolution.

\section{INTERNAL STRUCTURE OF THE MOUND}

The grid of SSDR profiles contains about 30,000 traces, each of which exhibits ten or more reflecting horizons. The pseudo-3-D image in fig.3 shows the reflection times of three of these (sea floor, BHSZ and top of the salt diapir) across the grid. It can be seen that the diapir pierces the BHSZ but does not reach the sea floor.

SSDR profiles in MC118 contain a number of shallow reflections that are generally continuous and conformable except in the region directly above the diapir. They also show a deeper discontinuous strong negative reflection that is thought to be generated by free gas below the BHSZ.

In addition to conformable shallow reflections and the deep strong negative reflection, the profile in fig. 4 shows deeper, faulted reflections, some of which exhibit negative polarity and might be generated by trapped gas. Regions of decreased reflection amplitude, called "wipeouts", extend upward from these faults and may

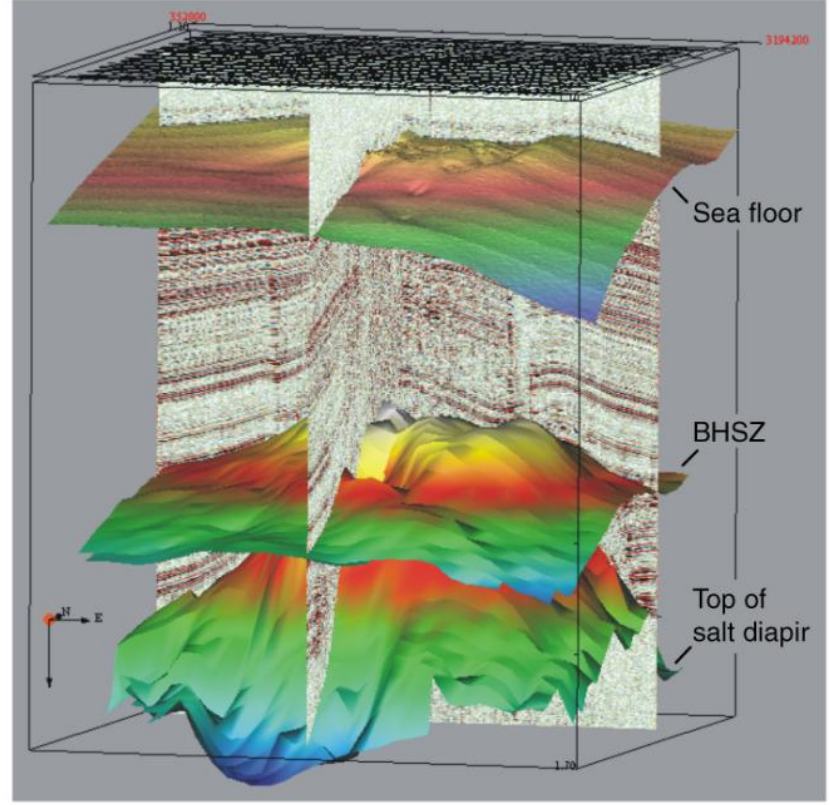

Fig.3 - Pseudo 3-D volume constructed from SSDR grid

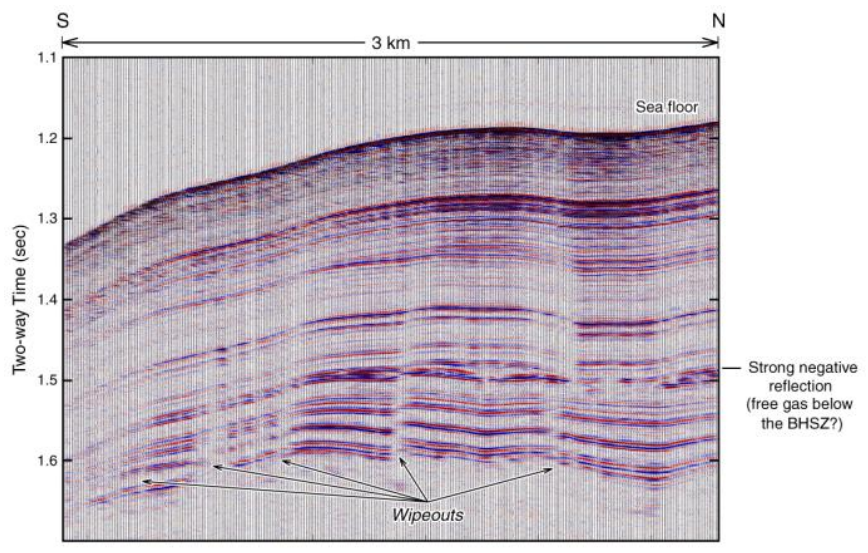

Fig.4 - SSDR profile showing conformable reflections, faults and "wipeouts" possibly caused by rising fluids

indicate migration pathways for rising gas and other hydrocarbon fluids.

Fig.5 shows a few traces across a feature in the NW Complex which, on the basis of local morphology, appears to be a tensional fracture zone. A $10 \mathrm{~m}$ gravity core into that feature recovered nodules of hydrate in fine-grained gaseous sediment. Geochemical analysis shows the hydrate-bound gases and dissolved gases to be thermogenic in origin and the geochemical conditions to be consistent with the presence of hydrate. The traces in fig.5 contain a short-period $(.05 \mathrm{~ms})$ signal which is thought to be energy scattered by inhomogeneities in the medium of propagation such as could be produced by localized occurrences of hydrate and/or free gas. 


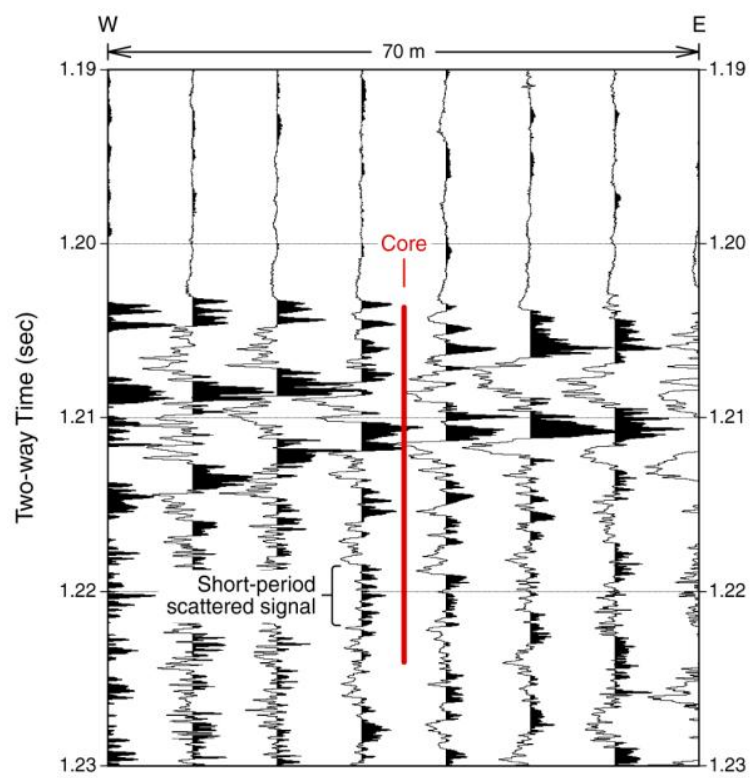

Fig.5 - SSDR traces near a core containing hydrate

Similar short-period signals occur widely on SSDR profiles in MC118. They are particularly common on profiles across a small shallow basin situated in the northern portion of the mound. Their visibility relative to the stronger reflected signals can be enhanced by applying the process of empirical mode decomposition as discussed in [3]. That has been done on the profile in fig. 6 where the scattered signal is seen to occur in a funnel-shaped region that extends from the sea floor down to a fracture that offsets the strong negative reflection. That shape is consistent with hydrocarbon fluids rising thru the fracture and spreading horizontally in the shallowest sediments. Thus the scattered signal might be useful for imaging the distribution of hydrate

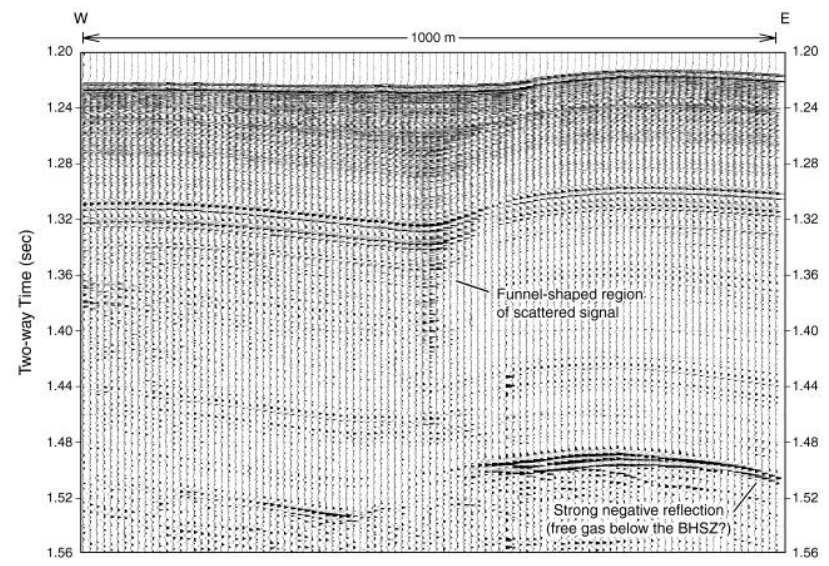

Fig.6 - SSDR profile showing funnel-shaped region of scattered signal rising above a break in the BHSZ nodules and/or pockets of free gas that sometimes occur in fine-grained sediment. If so, it would be a valuable tool for hydrate research.

\section{MicROBIAL ACTIVITY IN SEDIMENTS}

Core samples collected both within and without wipeout zones in the NW and SW Complexes have been used to study the role that sedimentary microbial activity plays in mound evolution [4]. Microbial activity was inferred from down-core concentration gradients of dissolved methane and sulfate, isotope gradients of methane, dissolved inorganic carbon, and authigenic carbonate, and organic matter elemental ratios. The hypothesis tested was that the wipeout zones indicate areas where sediments are exposed to elevated fluid flux and therefore should contain saturated methane concentrations and enhanced microbial activity from sulfate reduction, anaerobic oxidation of methane, and methanogenesis. It was found that the microbial activity was focused above the wipe-out zones yet was heterogeneous within the mound. Along with this spatial variability, evidence of temporal changes in microbial activity also was found. This biogeochemical survey provides evidence that the fluid flux at MC118 varies over time and that the microbial activity responds to such variability. It also suggests that sediments overlying wipeout zones are not always saturated with respect to methane, which has implications for the formation and detection of gas hydrate.

\section{ACKNOWLEDGMENTS}

Alessandro Bosman, Charlotte Brunner, Ken Sleeper and Paul Mitchell contributed substantially. Swath bathymetry data were recorded/processed by $\mathrm{C} \& \mathrm{C}$ Technologies of Lafayette, Louisiana, and reprocessed by the Department of Earth Science at the University of Rome "La Sapienza". SSDR profiles were acquired with the assistance of Specialty Devices Inc. of Plano, Texas, and recorded/processed using software by Lookout Geophysical Company of Palisade, Colorado. Funding for the observatory project is provided by the U.S. Department of the Interior (MMS), the U.S. Department of Energy (NETL) and the U.S. Department of Commerce (NOAA/NIUST). 


\section{REFERENCES}

[1] Sassen, R., H. H. Roberts, W. Jung, C. B. Lutken, D. A. DeFreitas, S. T. Sweet and N. L. Guinasso (2006): The Mississippi Canyon 118 Gas Hydrate Site: A Complex Natural System. OTC Paper \#18132, Houston.

[2] McGee, T., L. Macelloni, C. Lutken, A. Bosman, C. Brunner, R. Rogers, J. Dearman, K. Sleeper and J. R. Woolsey (2009): Hydrocarbon gas hydrates in sediments of the Mississippi Canyon Area, northern Gulf of Mexico. In Sediment Hosted Gas Hydrates: New Insights on Natural and Synthetic Systems, GeoSocLondon Spec Pub 319.
[3] Battista, B., C. Knapp, T. McGee and V. Goebel (2007): Application of empirical mode decomposition and Hilbert-Huang transform to seismic reflection data. Geophysics, 72, no.2.

[4] Lapham, L. L., J. P. Chanton, C. S. Martens, K. Sleeper, and J. R. Woolsey (2008): Microbial activity in surficial sediments overlying acoustic wipe-out zones at a Gulf of Mexico cold seep. Geochemistry, Geophysics, Geosystems, 9, no.6. 